\title{
Design and Development of Broaching Machine for Splines: A Case Study
}

\author{
Vrushabh A.Madnaik ${ }^{1}$, V.R.Naik ${ }^{2}$ \\ ${ }^{1} P G$ student at DKTE's Textile and Engineering Institute, Ichalkaranji, India \\ ${ }^{2}$ Associate professor at DKTE's Textile and Engineering Institute, Ichalkaranji \\ 1vrushabhmadnaik11@gmail.com \\ 2vrnaik66@gmail.com
}

\begin{abstract}
Broaching machine is mainly developed for special purposes where cycle times are less and number of job quantity is very high. Only at such points development of broaching machine is justified.

Design of such broaching machine is totally customizable. This paper discuss about frame design of machine, selection of guideways, design of hydraulic power pack for hydraulic operated machine and also selection of various cylinders, pipe fittings, mandrels, pump, motor, etc.

So, main purpose of this paper is designing the broaching machine which includes all its components. This paper focuses on selection of bought out parts too.
\end{abstract}

Keywords: frame design of machine, selection of guideways, design of hydraulic power pack, selection of hydraulic cylinders, pipe fittings, mandrels, pump and motor.

\section{Introduction}

Broaching is a manufacturing process designed to make custom, precision parts at high speeds. There are many types of broaching machines, but they all use tools to remove a certain amount of material from a blank or machined component. Depending on the broach being used, the process can create a circular hole, irregular exterior shape, a keyway or more irregular shapes. Similar to reaming, shaping and milling, broaching is a highly specialized, precise manufacturing process. Each broach machine is designed to create a single hole with maximum precision, speed and uniformity. In these regards, broaching is a highly competitive machining process, particularly when using soft metals and plastic components. Of course, there are certain applications where a broach machine may have reduced efficiency. Particularly hard metals may require routine tool conditioning, and every specialized cut requires a new broach tool [1].

Basically, broaching machines are used to increase the production rate and to increase the quality of process. Broaching machines are actual special purpose machines and can be made for the exact requirement in order to have higher production yield. This paper describes the actual designing that is required to build a broaching machine. Basis for this project is conceptual design of machine is being done and it is going to be a vertical broaching machine which is hydraulically operated. This is based on customer'srequirements and inputs which are regarding cost and space availability [2].

\subsubsection{Objectives}

1. Cycle time of job with this machine should be within 50-60 sec.

2. Machine should require less maintenance.

3. Machine should be robust enough. And should have less vibration, noise and can be run in automatic mode.

4. Machine should have a cleaning arrangement for the job.

5. Machine should have arrangements for easy chip management. 


\subsubsection{Methodology}

While designing any SPM machine customer's requirements are the key agenda. By keeping those at most priority, an exact problem statement is defined and then by brainstorming various possible solutions are discussed. After that, the best suitable solution is decided. Conceptual design for the same has been made. This step includes selection of various parts and their rough placements and it also comprises the sequence of operations that must be followed.

Then parametric design must be carried out where actual values of the parameters have been decided e.g., cutting speed, Actuator dimensions, Bearings, Structural member sizes, etc. By simulating the decided model various corrections have been made for possible fouling. Then final modeling is done where various aesthetic and safety considerations are incorporated. Once the Final model is prepared the manufacturing phase starts and is followed by testing and validation. This whole process is shown in fig. 1 below.

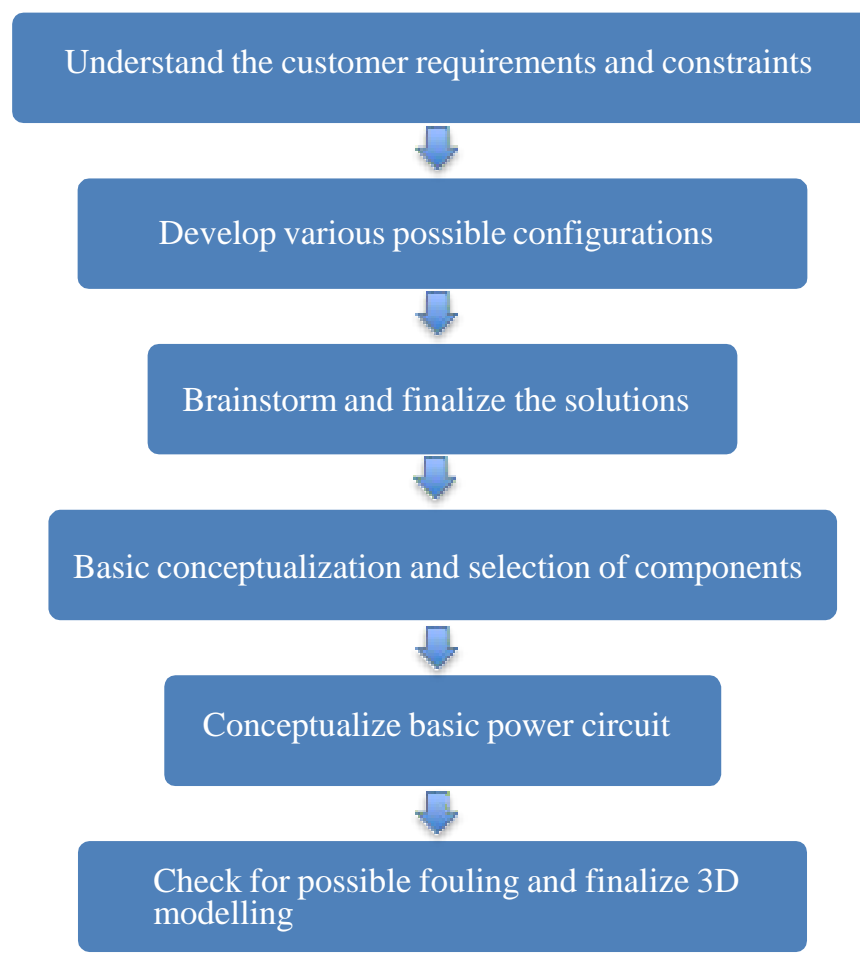

Figure 1. Design Methodology

\subsubsection{Actual customer requirements and inputs}
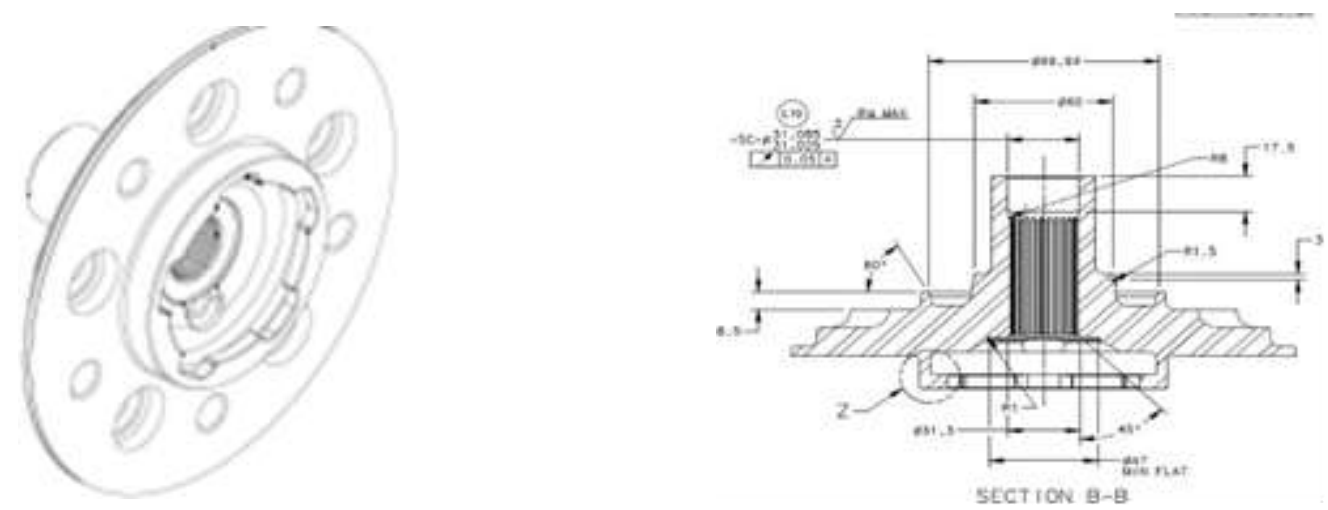

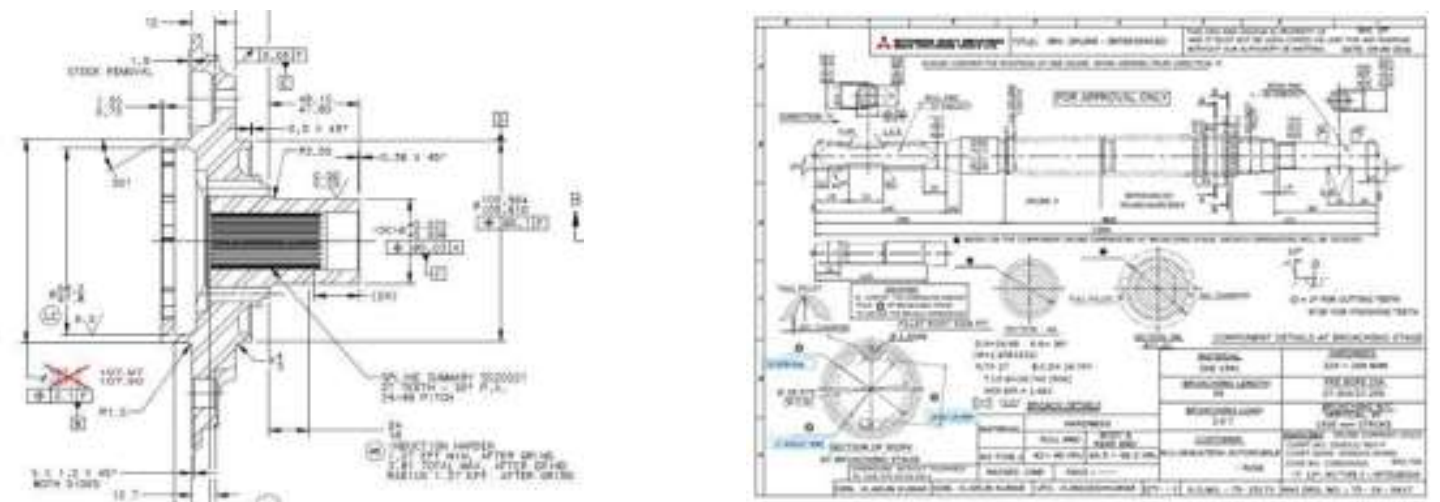

Figure 2. Input Drawings from Customer

Customer has provided various inputs like material of job, hardness, spline dimensions and specifications, current cycle time, required cycle time, no. of broach teeth, space availability and height of shed available. Some of these details are in the drawing shown in fig. 2 and some of them are documented separately. From these inputs the basic understanding is that splines are to be made on SAE 1541 material of given dimensions and broaching tools are going to be provided by customers whose dimensions and specifications are given in the sheet above. Current cycle time of a given job is $100 \mathrm{sec}$ which is supposed to be reduced to 50-60 sec. Customer also has a space constraint of $100 \mathrm{sq}$.ft. And Height constraint of $18 \mathrm{ft}$.

Modern vertical broaches are offered with both hydraulic and electro-mechanical drives. But hydraulic drives are the most common because they cost less [3]. Customer is having a floor constraint and wanted the system at an affordable price hence a vertical broaching machine with hydraulic controls is selected. Pneumatics is used for light operations like door closing and opening of job cleaning, etc.

\subsubsection{Basic concept design}

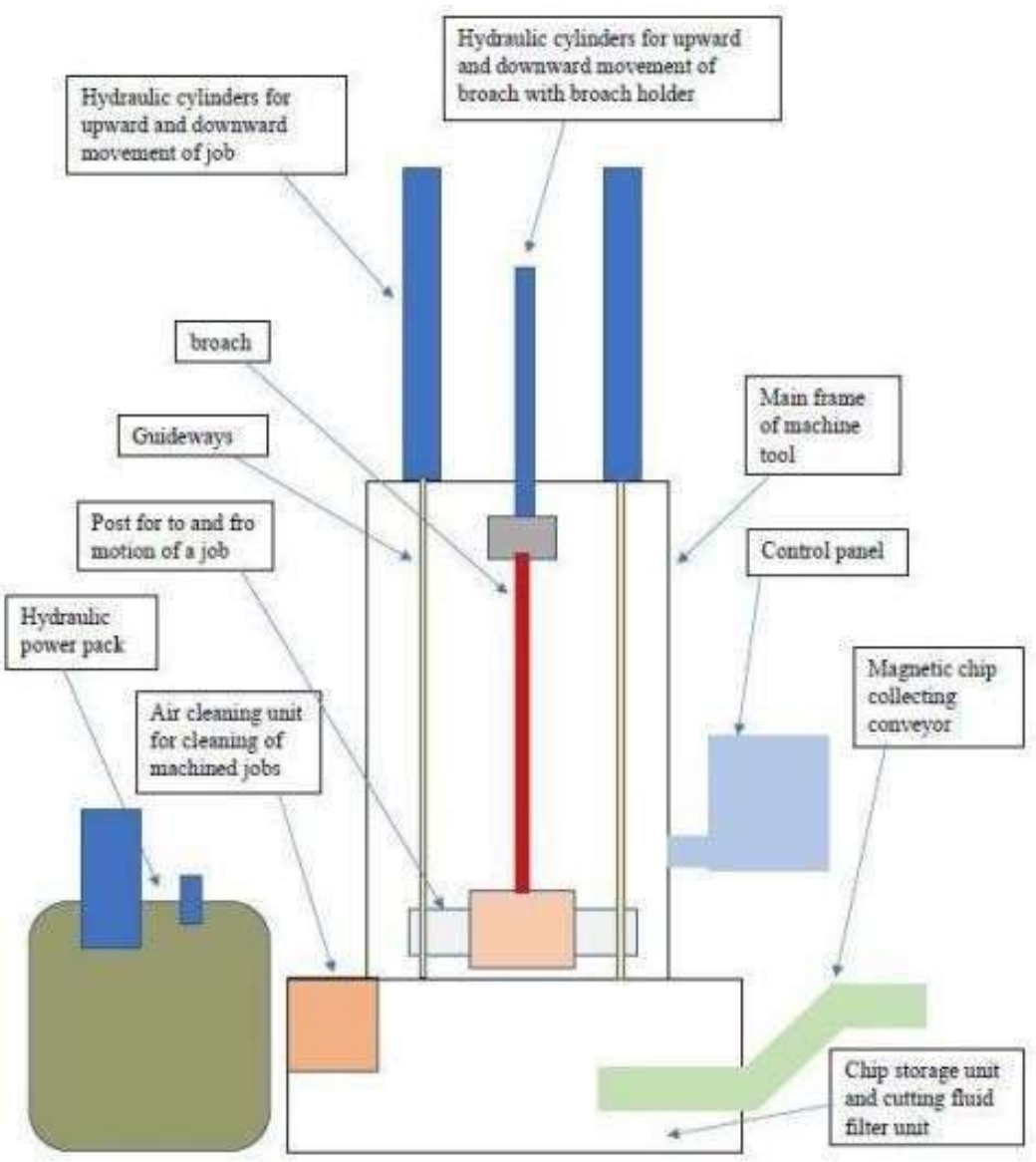

Figure 3. Basic Concept Drawing 
Above fig. 3 gives basic idea about essential components of machine tool. Machine frame is base of all the components which allows fixing of all the components on it and it is a stationary body. In order to facilitate the cutting operation there is need of relative motion between tool and workpiece and this is achieved with help of hydraulic actuators and the collets. Main hydraulic actuators are used for the movement of workpiece. And auxiliary actuator is used to facilitate the upward and downward movement of broach tool.

Collets are used for holding the broach stationary. Cross guide attached with actuators are used to provide transverse motion of workpiece. To give hydraulic power to circuit hydraulic power pack is used. Air cleaning unit and chip collection units are extra accessories provided with the machine.

\subsubsection{Calculation of broaching force}

To decide whether a particular work can be broached on a given machine and also to verify the strength of broach. It is essential to know the required broaching force $[4,5]$. Following formula gives us the broaching force in $\mathrm{kg}$, For Splines:

$\mathrm{P}=\mathrm{Ks} * \mathrm{~S} * \mathrm{~W} * \mathrm{Z} * \mathrm{C} * \mathrm{~K} \quad$ (Machine tool design handbook by HMT)

Where,

P: Broaching force, $\mathrm{kgf}$

Z: Number of teeth cutting at a time C: Rise per tooth, in mm from fig.4

S: No. of splines

W: Width of spline, $\mathrm{mm}$

Ks: Specific cutting force, in $\mathrm{Kgf} / \mathrm{mm} 2$ from fig. 4

$\mathrm{K}$ : Blunt broach factor (can be assumed to be 1.25 to 1.4 )

The value of Specific cutting force varies with the depth of cut as shown in table and accompanying graph.
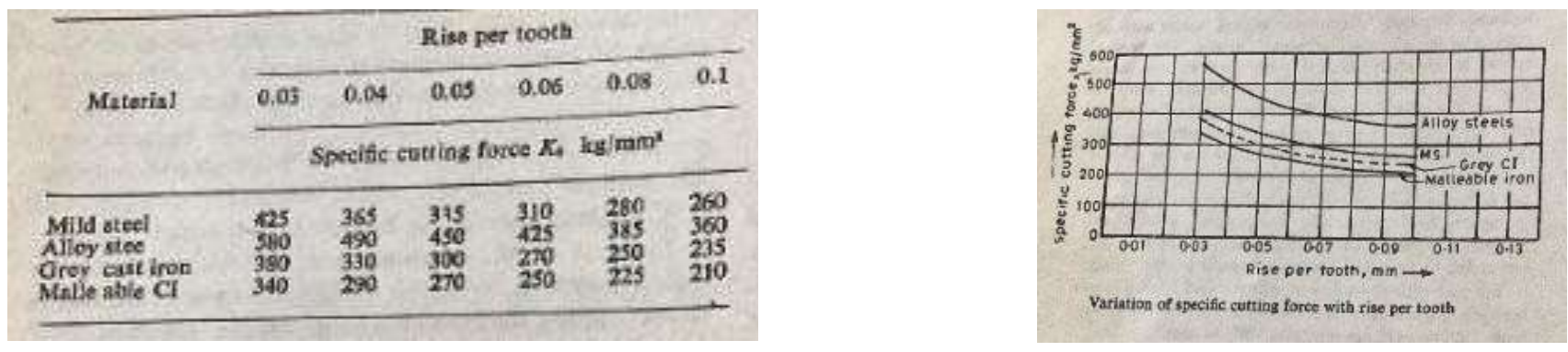

Figure 4. Specific Cutting Force and Depth of Cut References

$\mathrm{Ks}=350 \mathrm{~kg} / \mathrm{mm} 2$ (Given by customer) Pitch $=1.4 *$ (length of cut in $\mathrm{mm}$ ) 0.5 Broaching length $=54 \mathrm{~mm}$ Pitch $=1.4 *(54) * 0.5=10.41 \mathrm{~mm}$

$$
\begin{aligned}
\mathrm{Z} & =(\mathrm{L} \max / \text { pitch })+1 \\
& =(54 / 10.41)+1 \\
& =6.1873 \\
\mathrm{~S} & =27 \\
\mathrm{~W} & =1.66 \mathrm{~mm} \mathrm{~K}=1.25 \\
\mathrm{C} & =0.0385 \text { (as per customer broach) } \\
\mathrm{P} & =\text { Broaching force }=\mathrm{Ks} * \mathrm{~S} * \mathrm{~W} * \mathrm{Z} * \mathrm{C} * \mathrm{~K} \\
& =350 * 27 * 1.66 * 6.1873 * 0.0385 * 1.25 \\
& =4671.02 \mathrm{~kg}
\end{aligned}
$$

By considering factor of 1.30 for any irregularities and then the design broaching force becomes $=$ $4671 * 1$ is equal to nearly $6000 \mathrm{~kg}=6$ ton

Therefore, 6 Ton load machine tool needs to be designed and broach cutting length is $=969+41=1010$

And by considering some gap for start run and end run of tool, designed stroke length $=1200 \mathrm{~mm}$, Design Stroke length=1200 mm. After calculating the broaching force, cutting speed needs to be calculated in order to select the cylinders and design the hydraulic power 


\subsubsection{Selection of Cutting Speed}

Proper cutting speed depends on the work material and also on the type of broaching. Cutting speed is mainly decided by the hardness of tool materials and the surface finish requirement of the job. This is the reason why cutting speeds for various materials lie in the range of 3 to $30 \mathrm{~m} / \mathrm{min}$ with high-speed steel tools. Moreover, increase in cutting speed does not substantially reduce the cycle time as the cutting time is quite compared to non-cutting time in most of the broaching operations.

The recommended cutting speed ranges for different work materials are as follows:

Table 1. Cutting Speed Selection Table (Machine Tool Design Handbook by HMT)

\begin{tabular}{|r|r|r|r|r|}
\hline Material & $\begin{array}{r}\text { Hardness } \\
\text { BHN }\end{array}$ & $\begin{array}{r}\text { Cutting speed } \\
\text { m/min }\end{array}$ & $\begin{array}{r}\text { Rise per tooth } \\
\text { mm }\end{array}$ & HSS tool grade \\
\hline Free Machining steel & $100-200$ & $10-12$ & 0.1 & M2, M7 \\
\hline Carbon steel & $120-375$ & $3-8$ & 0.08 & M2, M7 \\
\hline Grey cast iron & $110-320$ & $7-30$ & 0.08 & M2, M7 \\
\hline Malleable CI & $110-400$ & $10-20$ & 0.08 & M2, M7 \\
\hline Aluminium alloys & $30-150$ & $10-20$ & 0.15 & M2, M7 \\
\hline Magnesium alloys & $40-90$ & $10-18$ & 0.15 & M2, M7 \\
\hline Copper alloys & $40-200$ & $8-10$ & 0.12 & M2, M7 \\
\hline
\end{tabular}

As per customer requirement cycle time should be near $60 \mathrm{sec}$ for one job so the cutting speed for carbon steel should be between $2-8 \mathrm{~m} / \mathrm{min}$. Hence, it is decided to keep this speed as $5.25 \mathrm{~m} / \mathrm{min}$ (as per experience) initially [6].

\subsubsection{Hydraulic Cylinder selection}

Before selection of the cylinder, highest power required must be known. So, let's calculate the power of machine: Power $=($ Cutting Force $*$ Velocity $) /$ Efficiency

$$
\begin{aligned}
& =(6 * 1000 * 9.81 * 5.25) / 0.95 \\
& =7.26 \mathrm{hp}
\end{aligned}
$$

So, let's go for $7.5 \mathrm{hp}$ power to be on safer side.

Now, decide the cylinder as per requirement of force and power available. should be:

It is decided to keep system pressure to be $7 \mathrm{MPa}$. To transmit force of 3 ton, bore area of cylinder

$=(3 * 1000 * 9.81 / 0.8) / 7 * 106$

$=5255 \mathrm{~mm} 2$

Which gives an idea that bore diameter should be $(5255 / 3.14)^{\wedge} 0.5=81.81 \mathrm{~mm}$. Hence, selected bore diameter $=100 \mathrm{~mm} 1000 \mathrm{~mm}$ stroke length is required as per above discussions but let's go for $1200 \mathrm{~mm}$ stroke in order to accommodate variety of jobs in the same machine. Hence the selected hydraulic cylinder is $\mathrm{CH} 2 \mathrm{~F}$ B 100 C 1200 by SMC [7].

The cylinders selected are going to use for actual pulling operation which is cutting operations but there is need of one more cylinder for the lifting of broach tool and its platform (Assembly for fixing/holding the tool)

While selecting this cylinder consideration is weight to be lifted and this weight includes weight of broach tool holder assembly + weight of upper collet + weight of tool $=48+6+7=61 \mathrm{~kg}$. These weights are calculated by drawing rough and exaggerated models of the same in CAD software.

Let's select the cylinder piston which bears $7 \mathrm{MPa}$ pressure and able to exert a force of $61 * 10=610 \mathrm{~N}$ Area required $=$ Force $/$ Pressure

$$
\begin{aligned}
& =(610) /(7 * 106) \\
& =87.14 \mathrm{~mm} 2
\end{aligned}
$$

After going through the catalogue of SMC, it is found that minimum possible c/s area is $550 \mathrm{~mm} 2$ 
which gives the force value of $550 * 7=3850 \mathrm{~N}$

Which can ultimately give us the factor of safety $=3850 / 610=6.31$

Hence, a cylinder with bore size $32 \mathrm{~mm}$, pressure $7 \mathrm{MPa}$, Stroke $600 \mathrm{~mm}$ is selected. Stroke calculation is made from cad drawing of a broaching machine.

Selected Hydraulic Cylinder is CH2F B 32 B 600 from SMC [7].

Now selection of 3rd pair of cylinders which are for transverse movement of workpiece having frictional resistance of linear guideways and guides. And this resistance is very small compared to other forces in the machine. Hence, selection is on the basis of pressure rating and stroke availability which is $7 \mathrm{MPa}$ and $140 \mathrm{~mm}$ resp.

So, the minimum bore diameter available is $32 \mathrm{~mm}$ and whose code is $\mathrm{CH} 2 \mathrm{~F}$ B $32 \mathrm{~B} 140$ from SMC [7].

\subsubsection{Linear Guideway Bearing Selection}

1) Selection of vertical linear guideways: By applying moment equilibrium, effective load on linear bearings is calculated. Loading condition is as shown in fig. 5 below:

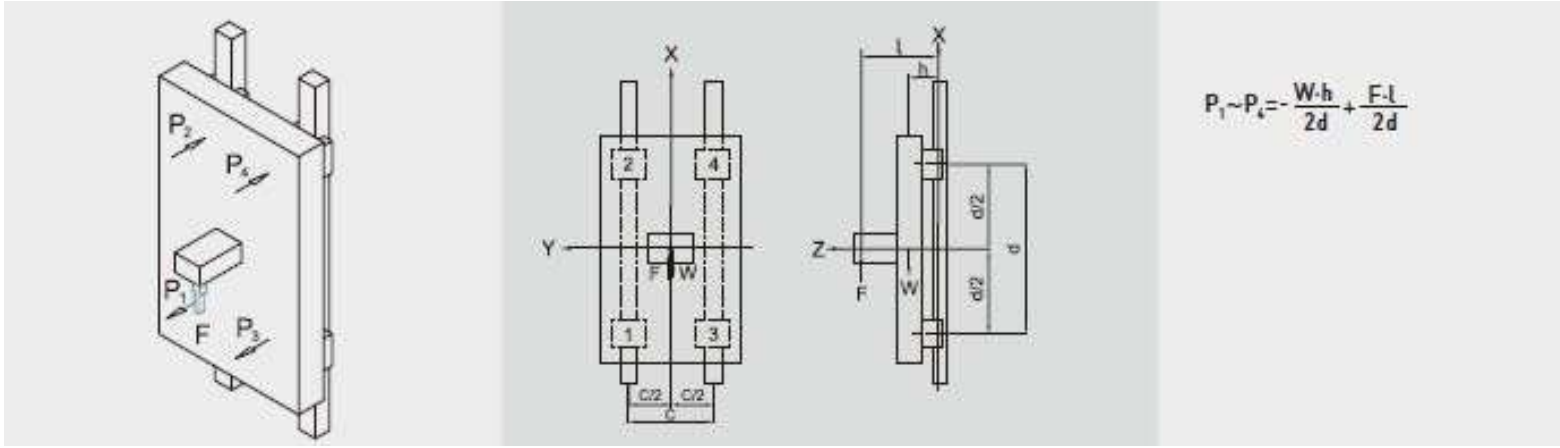

Figure 5. Effective Load Calculation Reference Diagram

In the above case cutting force is divided in two halves and calculating effective force using one half. Therefore, Effective load $=3000 * 9.81 * 250 / 2 * 200$

$$
=18.393 \mathrm{KN}
$$
referred.

HIWIN is one of the trusted brands in linear guideways hence while selection their catalogue has been

Let's select the linear guideway RGH45HA to check whether it is appropriate for the above use [8]. Let's use following fig. 6 for reference values.

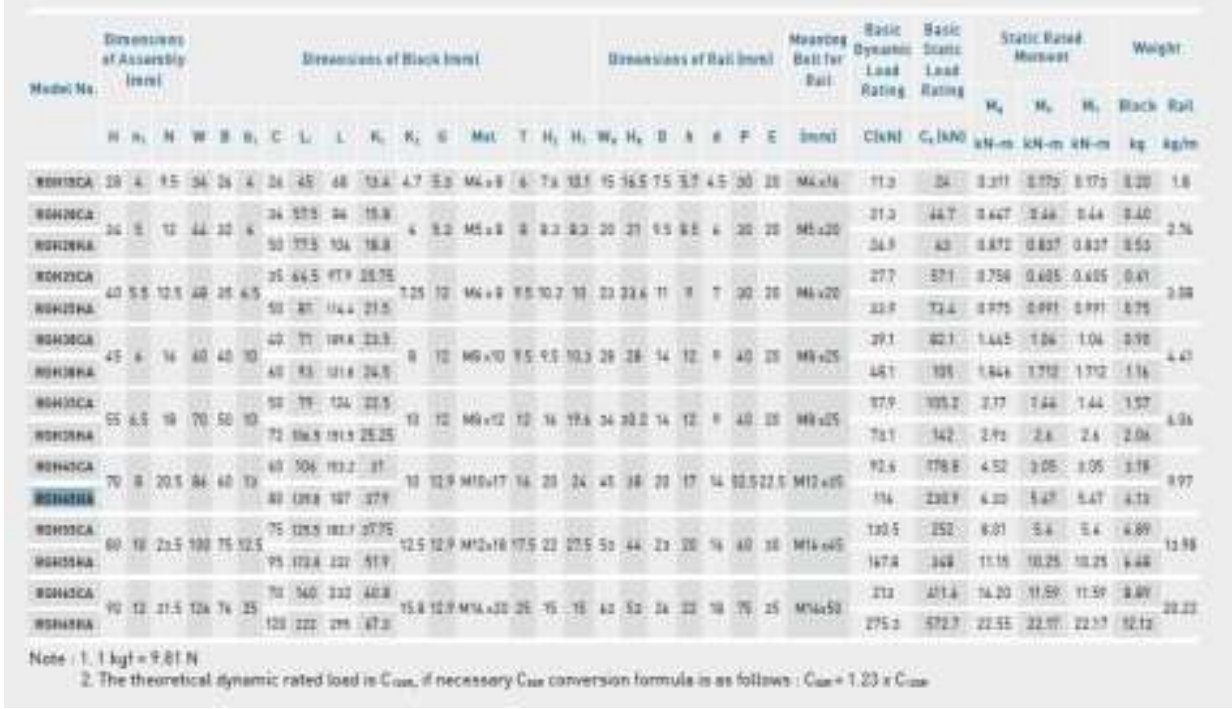

Figure 6. Linear Guideway Catalogue by Hiwin Image 1 
$\mathrm{L}=(\mathrm{C} / \mathrm{P}) 3 * 50 \mathrm{Km}$ for roller type linear guideways.

$=(116 / 18.393) 3 * 50$

$=12541.53 \mathrm{Km}$

Per day usage of main linear guideways for $16 \mathrm{Hrs}$. Shift $=$ Length of travel per minute $* 60 *$ Hours of shaft $=2400 * 80 * 16=3.072 \mathrm{Km}$

Life in terms of days $=12541.53 / 3.072=4082.53$ Days $=11$ Years (Approximately).

From the manufacturer's point of view the life of 11 Years is enough and it is expected that customers should ask for service after this much period of time.

After ensuring that life is within requirements. Let's check for static rated moments.

By considering loading condition as fixed support and point load in Centre the moment that is applying on linear guideways is $(\mathrm{PL} / 8)=6000 * 9.81 * 0.5 / 8=3.678 \mathrm{KN} . \mathrm{m}$ which is less than $5.47 \mathrm{KN} . \mathrm{m}$

Hence selected bearing is safe.

2) Selection of cross slide linear guideways: We have selected the cross-slide cylinders hence we know the Maximum force that can be applied

$=$ Pressure $* 3.14 * 0.25 * \mathrm{~d}^{2}$

$=7 * 10^{6} * 3.14 * 0.25 * 32^{2} 10^{-6}$

$=5.62 \mathrm{KN}$

Using Moment equilibrium let's calculate effective load $=5.62 * 30 /(2 * 200)$

$=0.4215 \mathrm{KN}$

As load is very less, we will be selecting the Basic guideway from RG series

Let's Check the RGH15CA for our use. And calculate the life in $\mathrm{Km}$. Use the following fig.7 for reference.

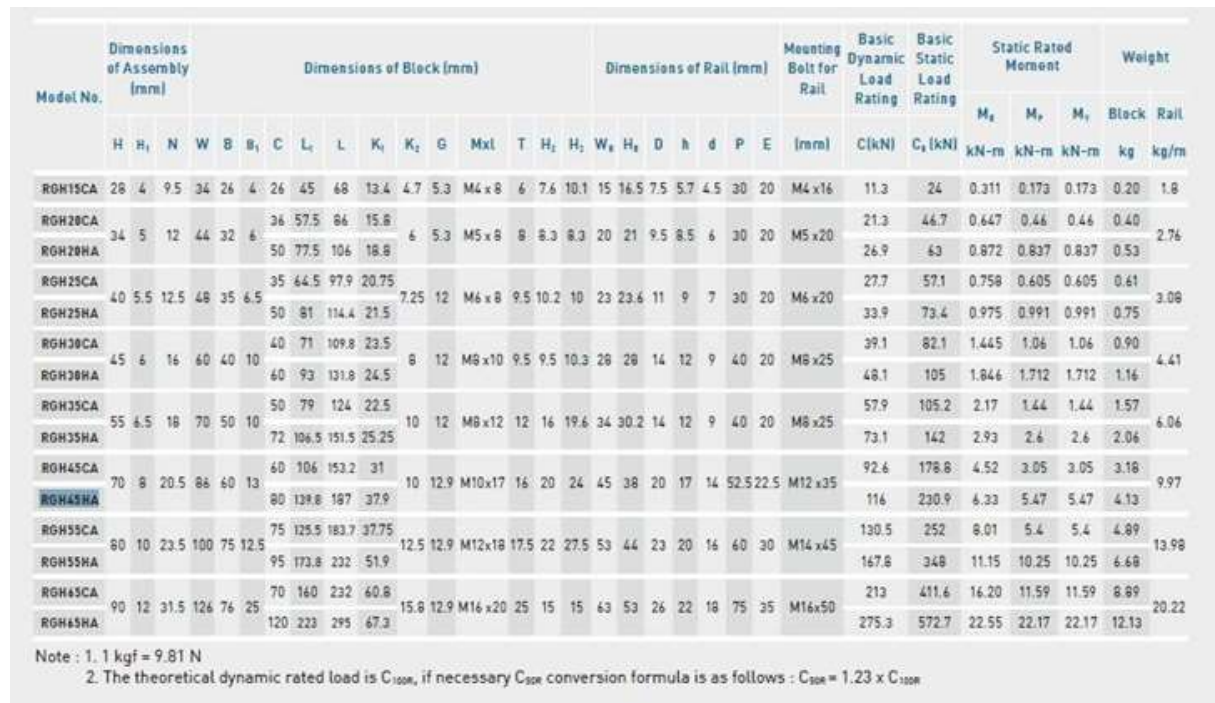

Figure 7. Linear Guideway Catalogue by Hiwin Image 2

$\mathrm{L}=(\mathrm{C} / \mathrm{P}) 3 * 50 \mathrm{Km}$

$=(11.3 / 0.4215) 3 * 50$

$=963413 \mathrm{Km}$

Travel of each bearing per day $=$ Travel per minute $* 60 *$ Hours per shift

$$
\begin{aligned}
& =0.4 * 80 * 16 \\
& =0.512 \mathrm{Km}
\end{aligned}
$$

Life in No. of Days $=3675129$ days

Life in terms of Years $=10068$ Years (Approximately)

This is Nearly Infinite. So, the selected bearing is appropriate. Therefore, Linear Guideway selected for cross slide is RGH15CA [8]. 


\subsubsection{Design of hydraulic power pack}

Designing of hydraulic power pack involves selection of all of its components like storage tank capacity, electric motor gear pump, solenoid valves oil filter, air breather and level indicator. Their selection is elaborated further in detail.

Hydraulic oil storage tank function is just to hold the oil and that must be rigid enough to sustain its own weight so as per standards and practices $5 \mathrm{~mm}$ sheet is used for manufacturing the tank and minimum welding is done in order to close it to avoid the leakages.

Let's summarize the selected hydraulic cylinders and their speeds in order to know the size of the hydraulic fluid tank to supply sufficient amount of fluid to the system.

Table 2. Selected Hydraulic Actuators Details

\begin{tabular}{|c|c|c|c|c|c|c|}
\hline Sr. No. & Model No. & Name & $\begin{array}{c}\text { Quantit } \\
\text { y }\end{array}$ & $\begin{array}{c}\text { C/s Area } \\
\left(\mathrm{mm}^{2}\right)\end{array}$ & $\begin{array}{l}\text { Velocity } \\
\text { (m/min) }\end{array}$ & $\begin{array}{l}\text { Discharge } \\
(1 / \mathrm{min})\end{array}$ \\
\hline 1 & CH2F B 100 C 1200 & $\begin{array}{l}\text { Main } \\
\text { Hydraulic } \\
\text { Cylinder }\end{array}$ & 2 & 5388 & 6 & 64.65 \\
\hline 2 & CH2F B 32 B 600 & $\begin{array}{l}\text { Auxiliary } \\
\text { Hydraulic } \\
\text { Cylinder }\end{array}$ & 1 & 804 & 6 & 4.82 \\
\hline 3 & CH2F B 32 B 140 & $\begin{array}{l}\text { Cross Slider } \\
\text { Cylinder }\end{array}$ & 2 & 804 & 6 & 9.64 \\
\hline
\end{tabular}

From Above table 2 total discharge required per $\min =64.65+4.82+9.64=79.116$ liter $/ \mathrm{min}$. In general, the tank capacity should be 3 times the liter per min discharge required $=79.116 * 3=240$ liter (Approx.) so, tank of size $1200 * 600 * 500$ is selected and then fill the fluid appropriately. This size of tank will have a capacity of 360 liter. Gear pump inlet level is down. So, a higher size tank is to be chosen [9].

\subsubsection{Selection of Electric Motor, Gear Pump, Solenoid valves}

From above calculations, maximum power that is required is while actual cutting operation which is going to be near $7.5 \mathrm{hp}$. Hence use the 3 Phase induction motor of $7.5 \mathrm{hp}$ power rating. And from above value of discharge required and the pumps available in the market motor with RPM 1450 is selected.

Hence a motor from Hindustan Motors Pvt. Ltd with Power 7.5 hp @1450 RPM is selected.

By studying the sequence of operations, maximum discharge required per min is $64.65 \mathrm{l} / \mathrm{min}$. Hence look for the available options from Yuken's catalogue.

Selected gear pump is of discharge $76 \mathrm{l} / \mathrm{min}$ capacity and which can give the pressure up to $21 \mathrm{MPa}$ from Yuken. Part Number of the selected gear pump is PG3-525-U1-3-FVR.

In this way the gear pump and electric motor is selected and the maximum pressure that can be produced by the pump is 210 bar. Hence, solenoid valves of the rated pressure capacity $210 \mathrm{Bar}$ are selected.

As per market availability solenoid valves selected are of the Spica made 4DE-1-GS-110 and 4DE-06ES-110 which are having 120 1/min and 60 1/min rating resp. 


\subsubsection{Final Assembly}
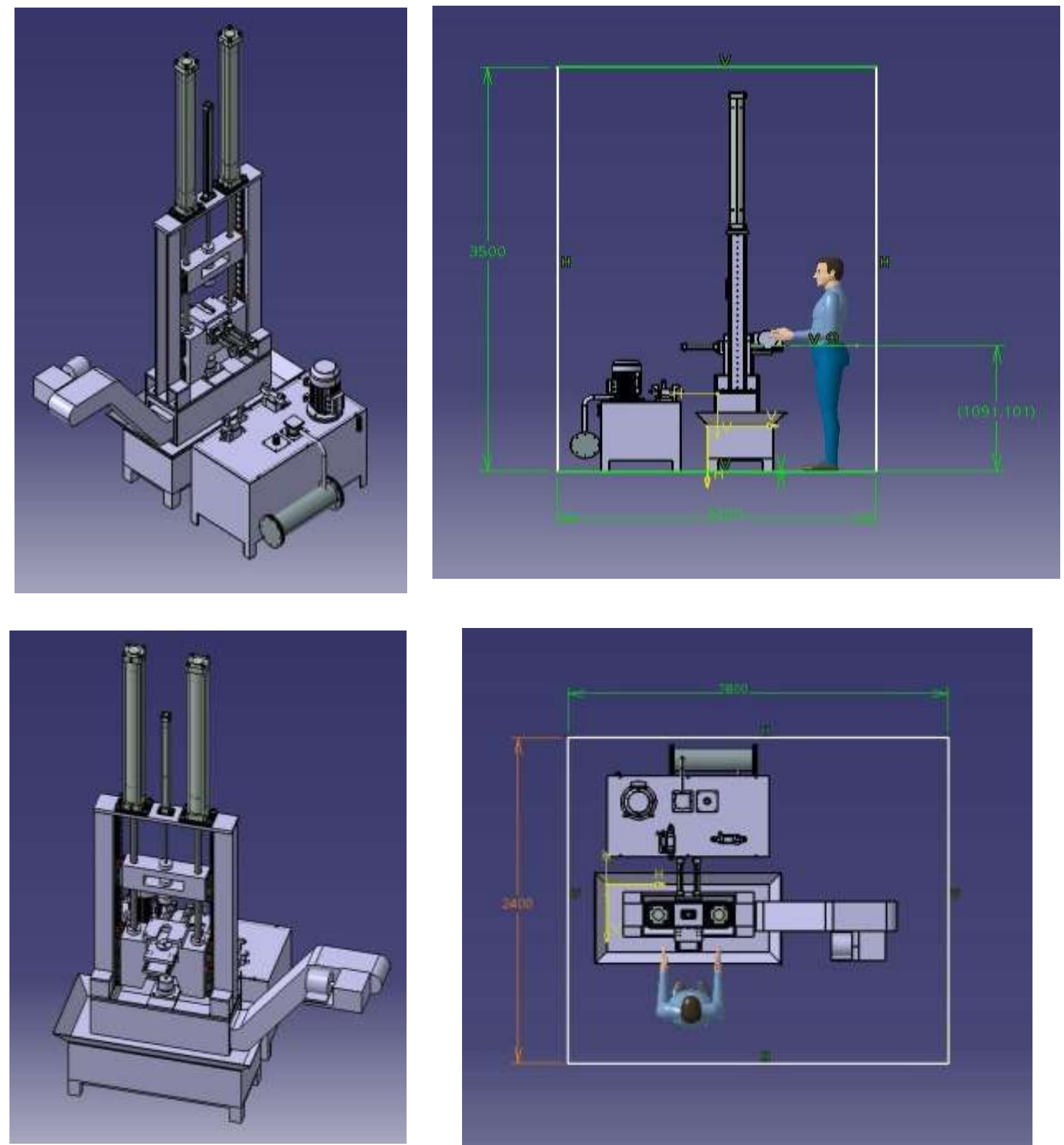

Figure 11. Final Assembly Image

Above fig.11 shows the ergonomic considerations and general assembly of the product. By keeping standard manikin in the model machine is ergonomically modified to reduce operator fatigue. In this way final $3 \mathrm{D}$ modelling is done. 


\subsubsection{Final product}
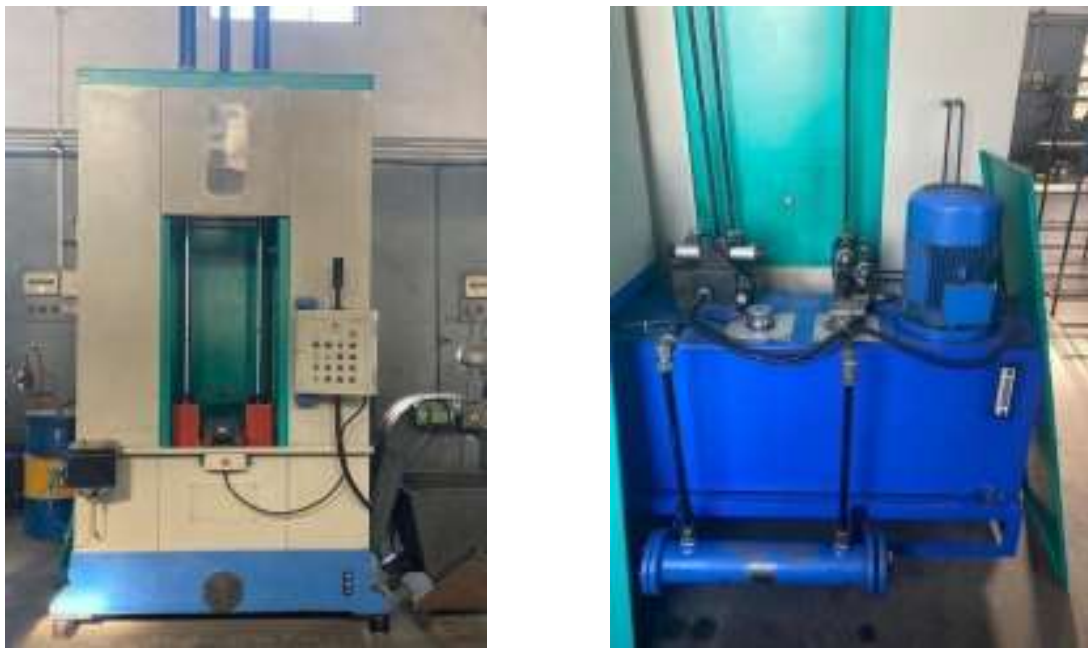

Figure 12. Final broaching machine

Above fig.12 shows the completely manufactured broaching machine which is exactly as per the drawings. Left hand side image shows front view of machine and right hand side image shows hydraulic power pack of machine. 


\section{Result and Discussions}

\subsubsection{CAE}

In this part the basic structure of broaching machines has been analyzed using software like Ansys, Hypermesh. Following are the details of constraints and results obtained during the analysis [10].

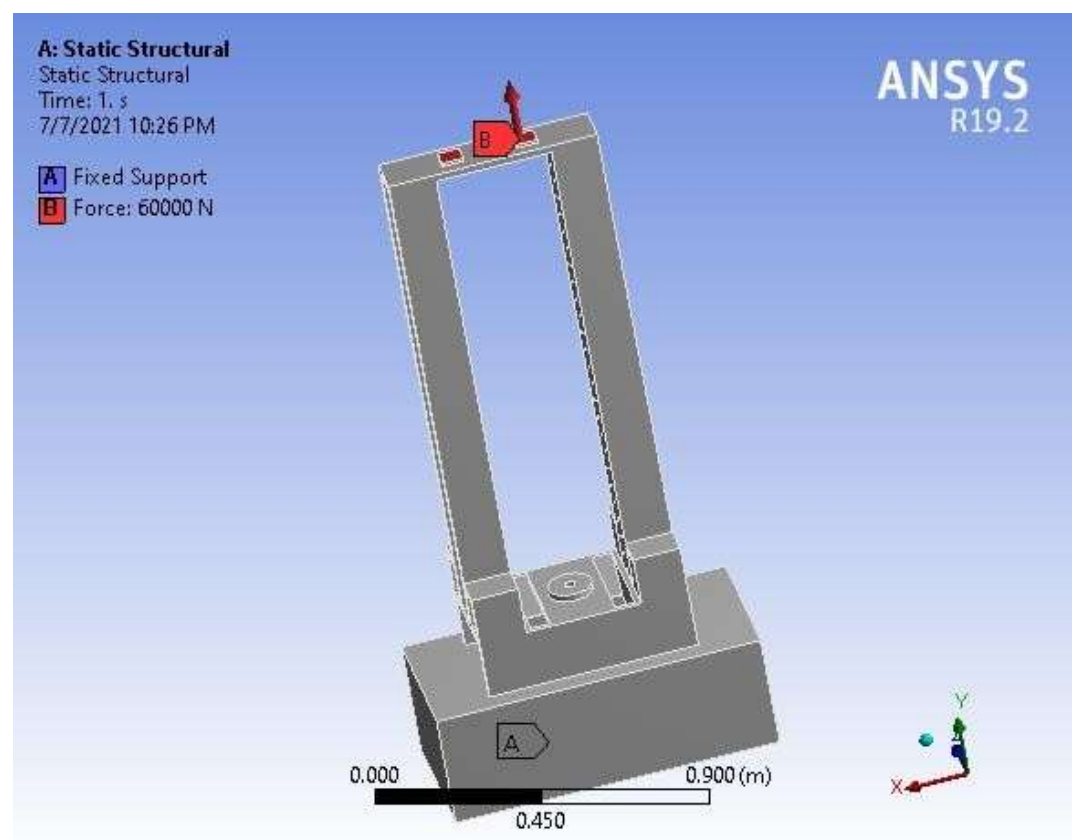

Figure 13. Static structural constraints and load

In the above fig.8, the base of the structure is fixed and the broaching force is applied at the point of cylinder mounting which is going to be a reaction force. And the magnitude of force is $60000 \mathrm{~N}$. This magnitude is calculated in the broaching force calculation. After this meshing is done to appropriate limits to get accurate analysis results. The material we are going to use is structural steel with tensile yield strength 250 $\mathrm{MPa}$ and ultimate tensile strength $460 \mathrm{MPa}$. Structural steel is ductile in nature. So, it is more appropriate to check stress results of Von mises theory of failure for a given structure. Below fig.9 shows that maximum stress in structure is $70 \mathrm{MPa}$ which gives minimum factor of safety of 3.56 which is pretty enough to sustain the loads.
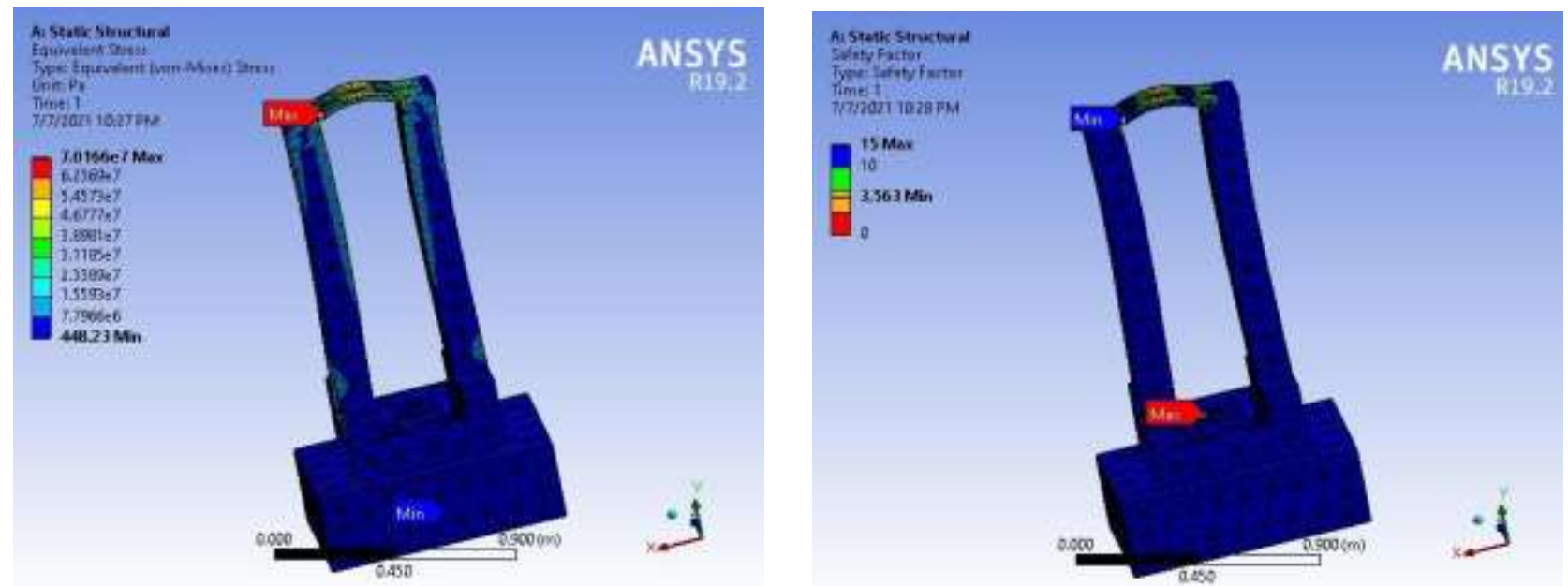

Figure 14. Results of Von Mises Theory 
So, from the above discussion it is clear that our structure is safe as per von mises theory. In order to get the exact tolerances on our machining job structure must be fabricated within the minimum tolerances and this structure is not supposed to deform under load hence total deformation and directional deformations of structures are analyzed under given loading conditions.

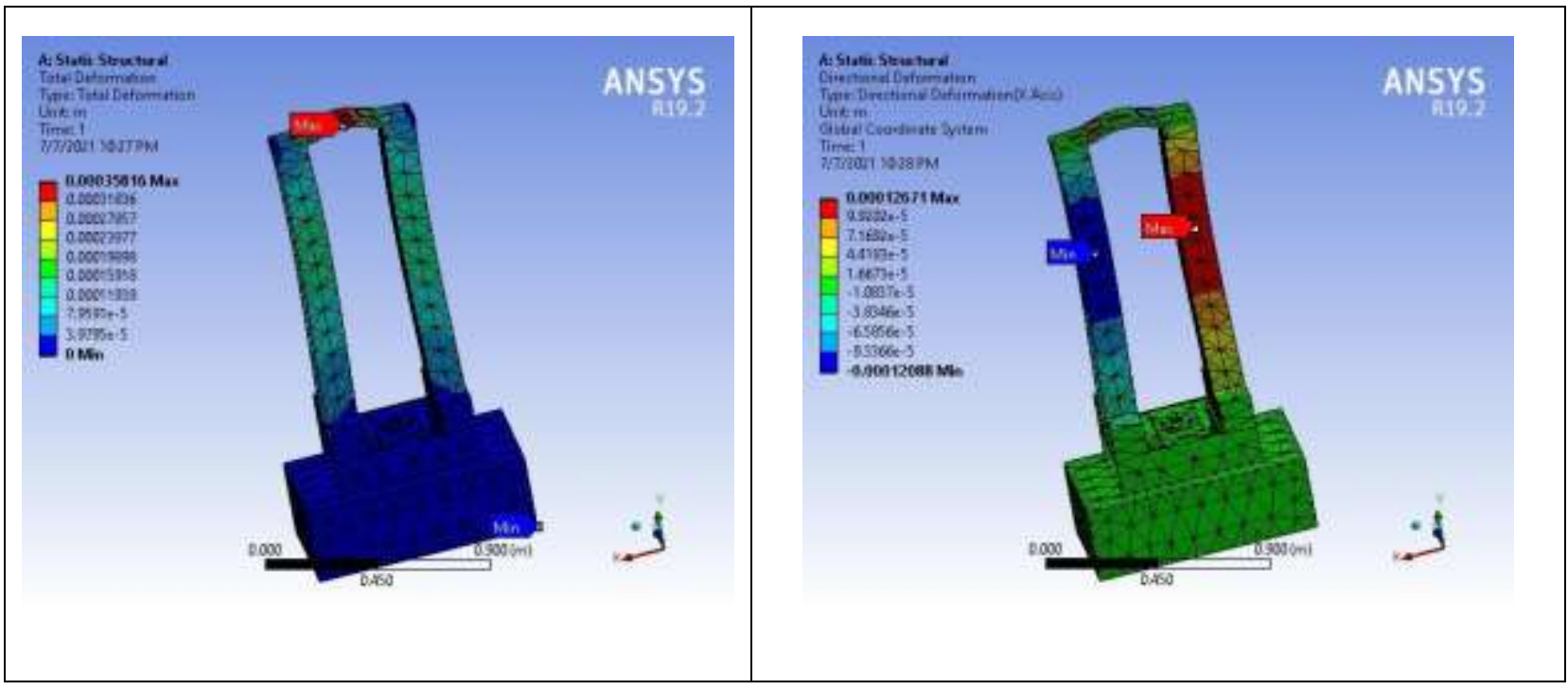

Figure 15. Deformation results

Table 3. Analysis results

\begin{tabular}{|c|c|c|c|c|c|}
\hline \multirow{2}{*}{ Sr. No. } & \multirow[b]{2}{*}{ Results } & \multicolumn{2}{|c|}{ Loading Condition 1} & \multicolumn{2}{|c|}{ Loading Condition 1} \\
\hline & & $\operatorname{Max}$ & Min & Max & Min \\
\hline 1 & Stress by M.D.E.T. & $70.16 \mathrm{MPa}$ & $448.23 * 10^{-6} \mathrm{MPa}$ & $99.62 \mathrm{MPa}$ & $\begin{array}{c}790.96^{*} 10^{-6} \\
\mathrm{MPa}\end{array}$ \\
\hline 2 & Stress by M.P.S.T. & $82.34 \mathrm{MPa}$ & $-12.37 \mathrm{MPa}$ & $116.14 \mathrm{MPa}$ & $-8.67 \mathrm{MPa}$ \\
\hline 3 & Stress by M.S.S.T. & $39.44 \mathrm{MPa}$ & $253.98 * 10^{-6} \mathrm{MPa}$ & $50.08 \mathrm{MPa}$ & $\begin{array}{c}434.71 * 10^{-6} \\
\mathrm{MPa}\end{array}$ \\
\hline 4 & $\begin{array}{l}\text { Directional } \\
\text { Deformation }\end{array}$ & $0.1267 \mathrm{~mm}$ & $-0.1208 \mathrm{~mm}$ & $1.48 * 10-2 \mathrm{~mm}$ & $\begin{array}{c}-1.03 * 10^{-2} \\
\mathrm{~mm}\end{array}$ \\
\hline 5 & Total Deformation & $0.3581 \mathrm{~mm}$ & $0 \mathrm{~mm}$ & $0.1855 \mathrm{~mm}$ & $0 \mathrm{~mm}$ \\
\hline 6 & $\begin{array}{c}\text { Factor of safety using } \\
\text { M.D.E.T. }\end{array}$ & 15 & 3.563 & 15 & 2.5094 \\
\hline 7 & $\begin{array}{c}\text { Factor of safety using } \\
\text { M.S.S.T. }\end{array}$ & 15 & 3.1686 & 15 & 2.4586 \\
\hline
\end{tabular}

Total deformation is $0.358 \mathrm{~mm}$ and directional deformation $0.126 \mathrm{~mm}$ which is under limits in order to get final job within its tolerances. So, from above discussions it is clear that structure is perfectly suitable for given loads. Simultaneously structure has been checked for other theories of failure to which it is safer and their results are tabulated above. In above table, results of 3 theories of failure are elaborated. From those maximum distortion energy theory is the most appropriate theory for ductile materials under triaxial state of stress. 


\subsubsection{Final Machining Output}
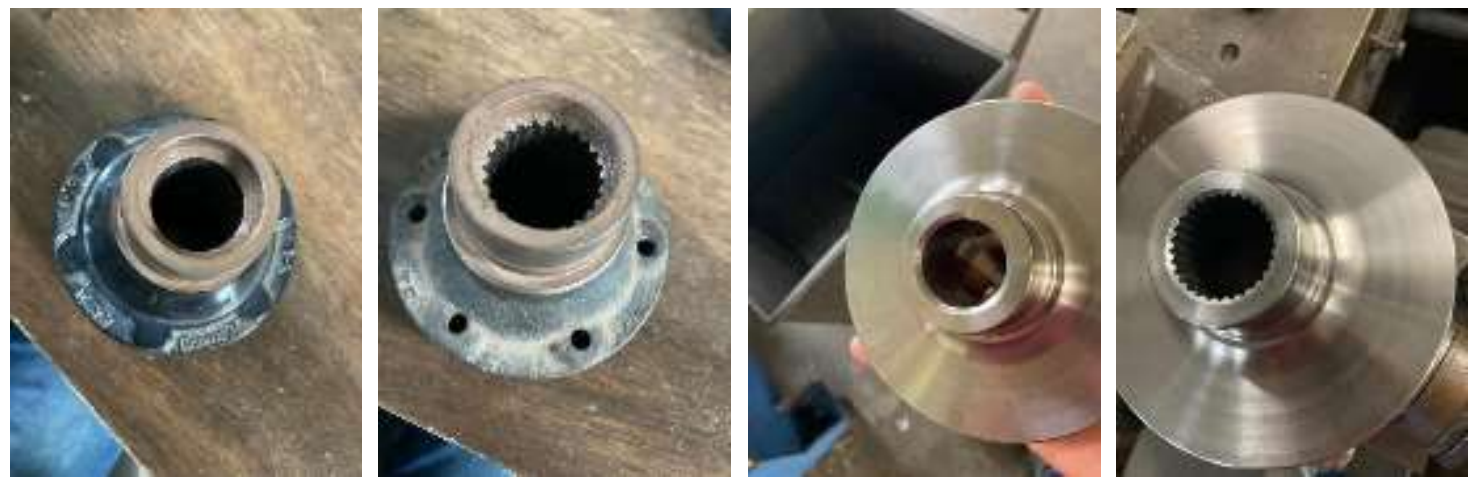

Figure 16. Before-After of Actual Job

After the broaching machine was ready, various job trials were done on it. Machined jobs were checked with help of go and no go gauges and it is found that quality parameters of $90 \%$ of jobs were confirming to requirements. Then by some fine tuning of machine this percentage has been raised to $95 \%$. This amount of accuracy was acceptable from customer.Fig.13 Shows the before after of the machined job.

\section{CONCLUSION}

From above analysis results conclusion is that the designed structure is safe enough to carry all the loads. And after manufacturing and trials it is pretty clear that the machine performs well to fulfill its functionality. Machined jobs are falling within their tolerances and auto cycle is also running as per the expectation without any fouling. At the same time cycle time achieved is fulfilling the customer expectation. Machine is equipped with the air cleaning unit and magnetic belt conveyor for easy chip removal.

\section{REFERENCES}

[1] Malyadri Akula, K. Chandra Sekhar, Akula Nagendra "Design and Analysis of Broach Tool for Splines", International Journal of Advanced Engineering Technology, Vol. IV, Issue I, January-March 2013.

[2] M. Sai Kumar, M. Sagar "Design and Development of Square Hole Broaching Machine”, Vol.6, Issue.3, MayJune 2018.

[3] Rahul B. Pandhare, Rajesh M. Metkar "Design of Semi-Automatic Hydraulic Broaching Machine-A Review”, ISSN: 2278- 0181, Volume 5, Issue 2, Special Issue - 2017.

[4] Mc Graw Hill Publications, HMT Machine Tool Design, Vol. 3, March 2000, pp.226-245.

[5] Balaji D. Tandle, K. Nagarjuna "Design and manufacturing of square broach tool", IOSR Journal of Mechanical and Civil Engineering, e- ISSN: 2278-1684, p-ISSN: 2320-334X, pp. 75-82.

[6] Changming Zhang, Anle Mu, Qi Shen and Hui Zhang "Simulation on Cutting Forces and Cutting Temperature in Broaching of 300M Steel”, Thermal Science, Vol. 23, Issue 05, pp. 2585-2594.

[7] Mr. S. B. Herwade, Prof. A. M. Naniwadekar "Reliability Analysis of Vertical Broaching Machine by Fault Tree Analysis (FTA) Method", Reliability Analysis of Vertical Broaching Machine by Fault Tree Analysis (FTA) Method, Volume 3, Issue 04, September 2016.

[8] Amit U. Pawar, Apurv A. Wagh and D. U. Patil "Design of Linear Motion Guideways", International Journal of Engineering research and Science and Technology, Vol. 4, No. 2, May 2015.

[9] Vaibhav D. Paliwal, Vaibhav H. Bankar "Design and analysis of hydraulic power pack", International Engineering Journal for Research and Development, Vol 3, Issue 1, E-ISSN No:2349-0721.

[10] P. Khanjanzadeh, H. Amirabadi, J. Sadri "Design of Broaching Tool Using Finite Element Method for Achieving the Lowest Residual Tensile Stress in Machining of Ti6Al4V Alloy", Vol. 33, Issue 4, April 2020, pp.657-667. 